\title{
An extremely rare variant of mixed total anomalous pulmonary venous connection
}

\author{
Kamal Gupta, Navin Agrawal, Anand Subramaniam, Jayaranganath Mahimarangaiah
}

Department of Cardiology, Sri Jayadeva Institute of Cardiovascular Sciences \& Research, Bangalore, Karnataka, India

\section{Correspondence to} Dr Navin Agrawal, drnavinagrawal@gmail.com

\section{Accepted 13 March 2014}

\section{DESCRIPTION}

A 6-month-old infant was referred for cardiac evaluation in view of respiratory distress of 1-month duration. Chest X-ray revealed the presence of cardiomegaly with features differential plethora with the right lung field showing higher vascularity and grade II pulmonary venous hypertension as compared to the left lung field which showed grade I pulmonary venous hypertension suggestive of partially obstructed flow of the right pulmonary venous system (figure 1). Transthoracic echocardiography showed a dilated right atrium and right ventricle, a large non-restrictive ostium secundum atrial septal defect of size around $1 \mathrm{~cm}$ with a right-to-left shunt and severe pulmonary arterial hypertension (figure 2A). Detailed echocardiographic evaluation revealed increased flow velocities in the superior and inferior vena cava with a pulmonary venous confluence draining to the superior vena cava (SVC; figure 2B; videos 1 and 2).

CT angiogram was carried out to delineate the pulmonary venous anatomy. CT angiographic image demonstrated the right upper and lower pulmonary veins joining to form a confluence and draining into the portal vein. The left upper and

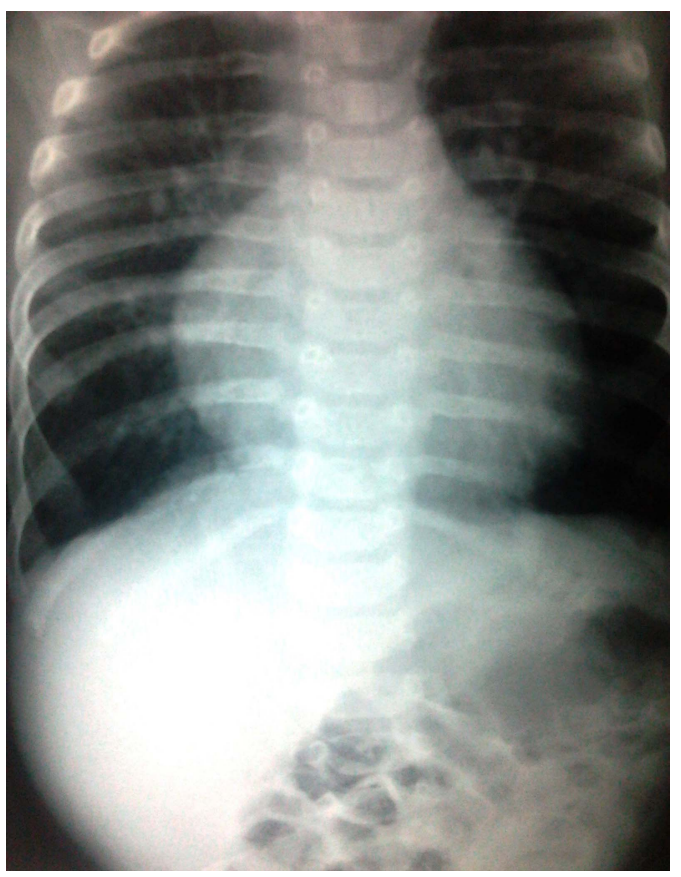

Figure 1 Chest $\mathrm{X}$-ray revealed the presence of cardiomegaly with features of differential plethora with the right lung field showing higher vascularity and grade II pulmonary venous hypertension as compared to the left lung field which showed grade I pulmonary venous hypertension.

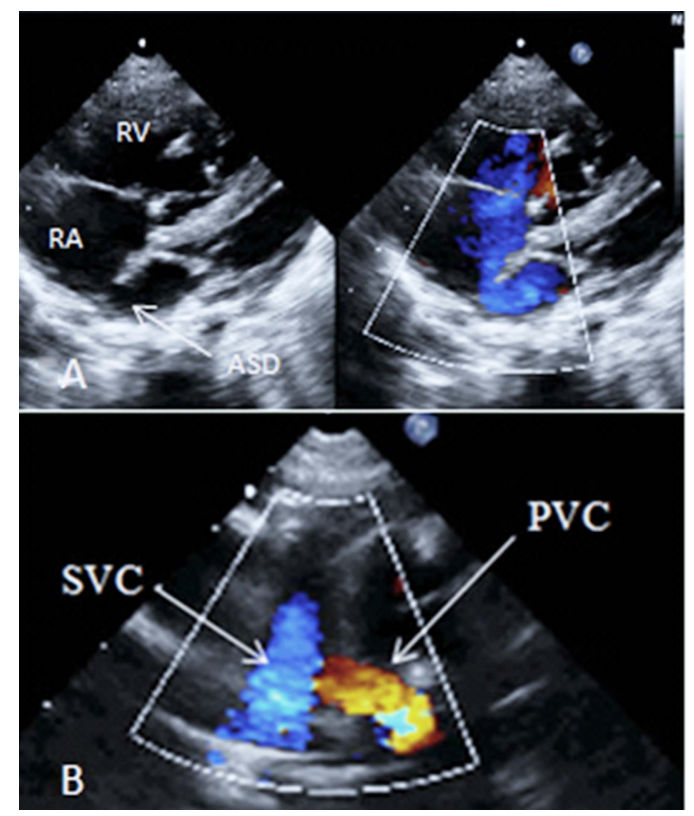

Figure 2 (A) Echocardiogram showing dilated right atrium and right ventricle with a large and unobstructed ostium secundum atrial septal defect (ASD). Colour Doppler demonstrates right to left shunt through the ASD without any evidence of turbulence. (B) Colour Doppler imaging showing pulmonary venous confluence draining into superior vena cava.

lower pulmonary veins formed a confluence and were seen draining into the superior vena cava unlike the more common pattern of drainage into the innominate vein before draining into the SVC (figures 3 and 4). Such a combination of supracardiac and infracardiac total anomalous pulmonary venous return is extremely rare with very few previous case reports. ${ }^{1-3}$ The patient subsequently underwent surgical correction of the anomaly and has been doing well at 3 months of follow-up.

Total anomalous pulmonary venous return is a rare cardiac anomaly of which the supracardiac type is the most common followed by the cardiac and infracardiac types while the mixed type is much less common. ${ }^{2} 4$

This case is important as an illustrative learning experience for cardiologists and paediatricians dealing with infants with congenital heart disease because early recognition and prompt management forms the key to deal with such cases of potentially correctable congenital heart disease which can be fatal very early in childhood if left uncorrected. 


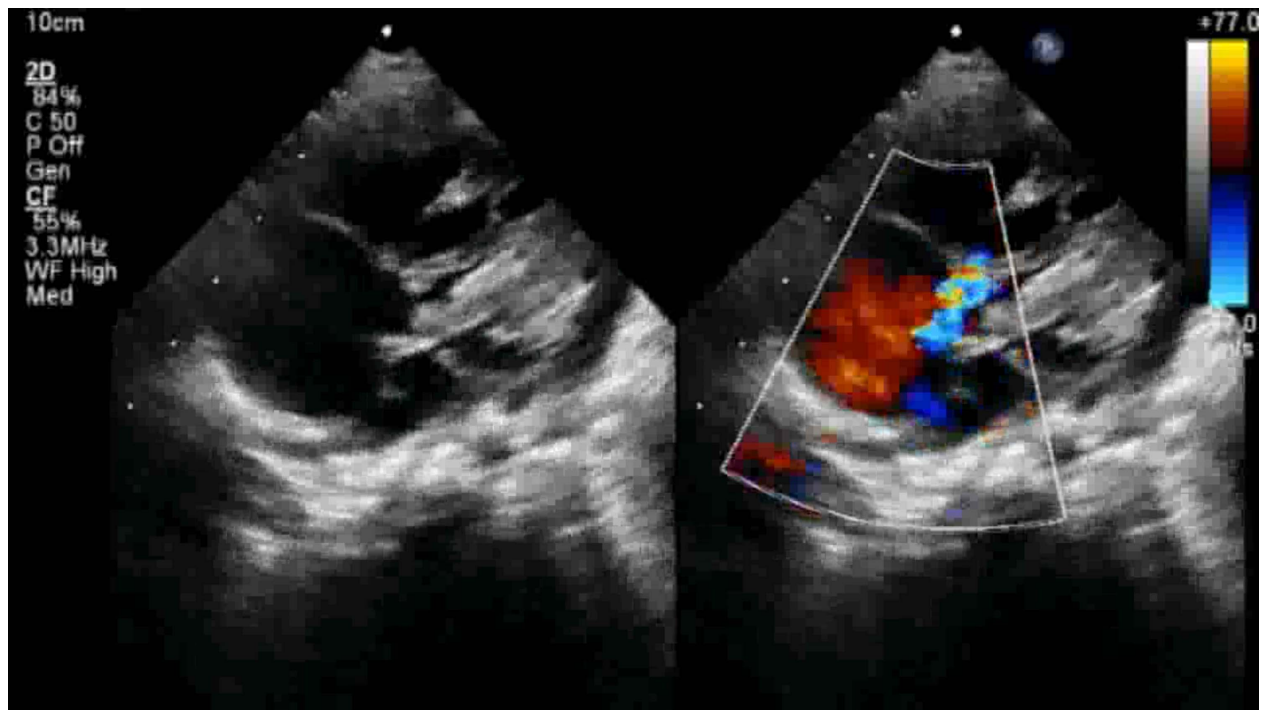

Video 1 Subcostal four chamber view showing dilated right sided chambers with right to left shunting across the ASD.

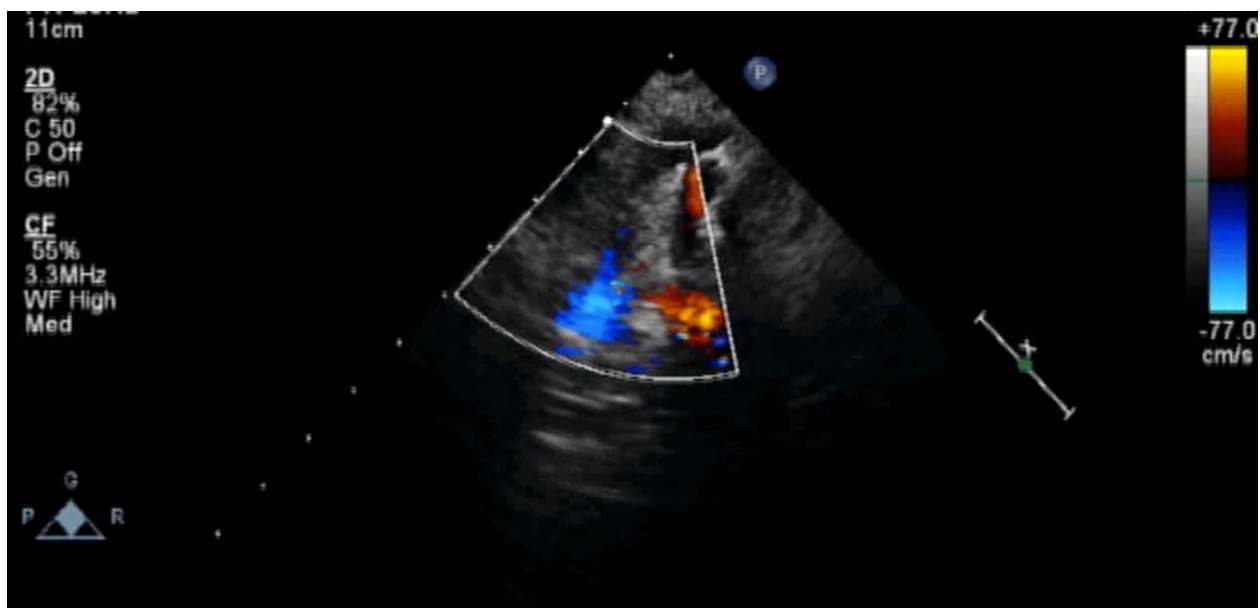

Video 2 Suprasternal view showing drainage of anomalous venous connection to the superior vena cava.

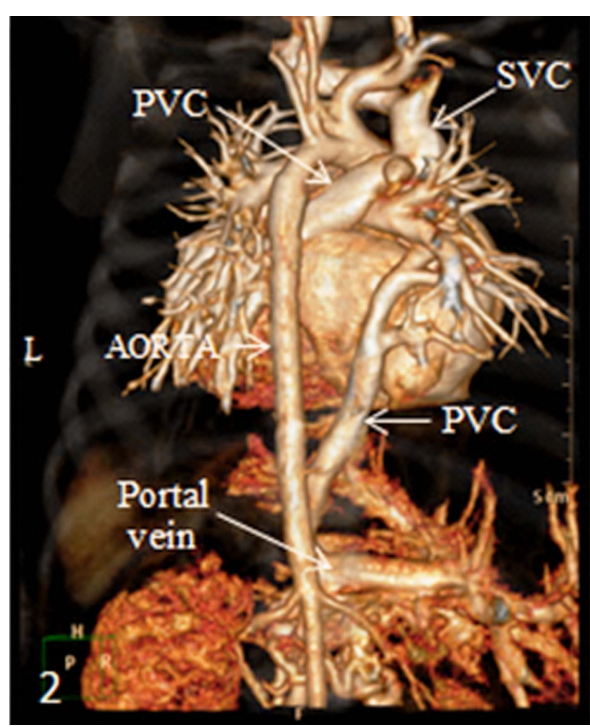

Figure 3 Three-dimensional-reconstructed CT angiographic image showing right upper and lower pulmonary veins (PVC, pulmonary venous connection) draining into the portal vein. Left upper and lower pulmonary veins are seen draining directly into the superior vena cava.

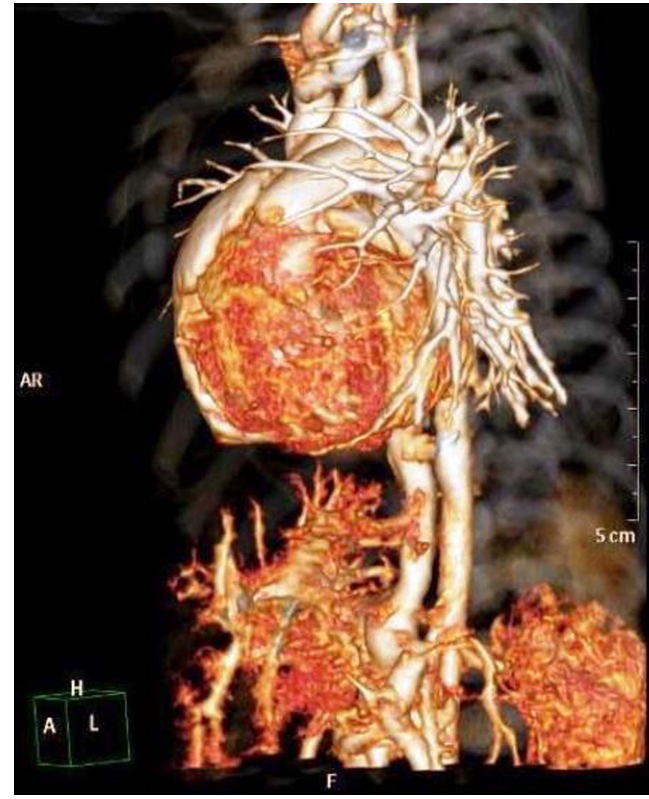

Figure 4 Sagittal image on the three-dimensional reconstruction of CT image showing the anomalous pulmonary venous connection. 


\section{Learning points}

- Echocardiography is the standard of care in the diagnosis of total anomalous pulmonary venous connection (TAPVC) although cardiac catheterisation or CT can be considered the gold standard investigation to provide a definitive diagnosis.

- Although in this case surgical therapy was successful, but this disease carries a high neonatal and early childhood mortality period, making early recognition and treatment the key to management in such cases as TAPVC is a potentially correctable life-threatening congenital cardiac disease.

- This case is an extremely rare morphological variation of the mixed form of TAPVC which itself is one of the rarest forms of TAPVC and can be an illustrative learning experience for clinicians and cardiologists.
Contributors All the authors have contributed to the drafting of the manuscript and helped in patient care.

Competing interests None.

Patient consent Obtained.

Provenance and peer review Not commissioned; externally peer reviewed.

\section{REFERENCES}

1 Imoto $\mathrm{Y}, \mathrm{Kado} \mathrm{H}$, Asou $\mathrm{T}$, et al. Mixed type of total anomalous pulmonary venous connection. Ann Thorac Surg 1998;66:1394-7.

2 Delisle G, Ando M, Calder AL, et al. Total anomalous pulmonary venous connection (report of 93 autopsied cases with emphasis on diagnostic and surgical considerations). Am Heart J 1976;91:99-122.

3 Kung GC, Gao H, Wong PC, et al. Total anomalous pulmonary venous return involving drainage above, below, and to the heart: a mixed bag. J Am Soc Echocardiogr 2004;17:1084-5.

4 Darling RC, Rothney WB, Craig JM, et al. Total pulmonary venous drainage into the right side of the heart; report of 17 autopsied cases not associated with other major cardiovascular anomalies. Lab Invest 1957;6:44-64.

Copyright 2014 BMJ Publishing Group. All rights reserved. For permission to reuse any of this content visit http://group.bmj.com/group/rights-licensing/permissions.

BMJ Case Report Fellows may re-use this article for personal use and teaching without any further permission.

Become a Fellow of BMJ Case Reports today and you can:

- Submit as many cases as you like

- Enjoy fast sympathetic peer review and rapid publication of accepted articles

- Access all the published articles

- Re-use any of the published material for personal use and teaching without further permission

For information on Institutional Fellowships contact consortiasales@bmjgroup.com

Visit casereports.bmj.com for more articles like this and to become a Fellow 